\title{
The Re-Emerging Role of Elective Pelvic Nodal Irradiation in High-Risk Node Negative Prostate Cancer
}

\author{
S. A. Mangar \\ Department of Clinical Oncology, Imperial College Healthcare NHS Trust, London, UK \\ Email: s.mangar@imperial.ac.uk
}

How to cite this paper: Mangar, S.A. (2017) The Re-Emerging Role of Elective Pelvic Nodal Irradiation in High-Risk Node Negative Prostate Cancer. Journal of Cancer Therapy, 8, 1135-1148. https://doi.org/10.4236/jct.2017.813097

Received: August 23, 2017

Accepted: December 10, 2017

Published: December 13, 2017

Copyright $\odot 2017$ by author and Scientific Research Publishing Inc. This work is licensed under the Creative Commons Attribution International License (CC BY 4.0).

http://creativecommons.org/licenses/by/4.0/

\begin{abstract}
The benefit of elective nodal irradiation (ENI) in combination with androgen deprivation therapy in high risk localized node negative prostate cancer has yet to be clearly defined. The potential gains in local control have been offset by the increased toxicity associated with pelvic radiotherapy, and recognition that historically the only trials to demonstrate a survival advantage in this group have been with androgen deprivation therapy. This review article considers the impact of pivotal randomized clinical trials conducted over the last thirty years on routine clinical practice, and how modern techniques may help to redefine radiotherapy as a necessary component for this group of patients.
\end{abstract}

\section{Keywords}

Prostate Cancer, Pelvic Radiotherapy, Clinical Trials, Androgen Deprivation Therapy, IMRT

\section{Introduction}

The clinical benefit of elective pelvic nodal irradiation (ENI) in the management of prostate cancer remains controversial and as yet unproven. Historically concerns have been raised with the increased gastrointestinal toxicity associated with pelvic radiotherapy, with questionable gains in overall survival over and above that of long term androgen deprivation therapy (ADT), which has long been considered the mainstay of treatment for advanced prostate cancer.

However, the question of pelvic radiotherapy is gaining renewed interest in high risk node negative prostate cancer especially as there is now increasing supportive data for the use ADT with prostate and pelvic radiotherapy in the management of node positive disease [1] [2] [3]. 
This review article considers the data from selected randomized controlled studies addressing the question of pelvic radiotherapy in high risk node negative disease, together with the optimum duration of ADT.

\section{Search Strategy and Selection Criteria}

Medline citations were searched under the terms "radiotherapy", "pelvic" and "prostate cancer" on $1^{\text {st }}$ September 2017. The initial search yielded 2254 publications. Only papers published in English since January $1^{\text {st }} 1980$ were included resulting in 2012 results. Of those, publications were only considered if they were phase three trials comparing prostate-only versus prostate and pelvic radiotherapy with either the whole cohort being clinically node negative or had a documented proportion of patient that were node negative. Studies on post-operative radiotherapy, or lymph node positive patients were not included. This resulted in 24 selected studies (Figure 1).

\subsection{Rationale of Combining ADT with Radiotherapy}

The rationale for utilising radiotherapy stems from the belief that the cytotoxic effect would permit local control of the disease which in the long term would translate into a cancer cure without necessarily impairing the patient's quality of life.

Combining radiotherapy with ADT has certain advantages. Firstly neoadjuvant $\mathrm{ADT}$ may allow for at least a $30 \%$ cytoreduction of the prostate target volume [4], thereby reducing the dose and hence toxicity to adjacent tissues such as the bladder and rectum. Secondly there may well be a synergistic effect with ADT and radiotherapy. Preclinical studies in mouse models have shown that hormonal treatment can act as a radiosensitizer allowing for a significant

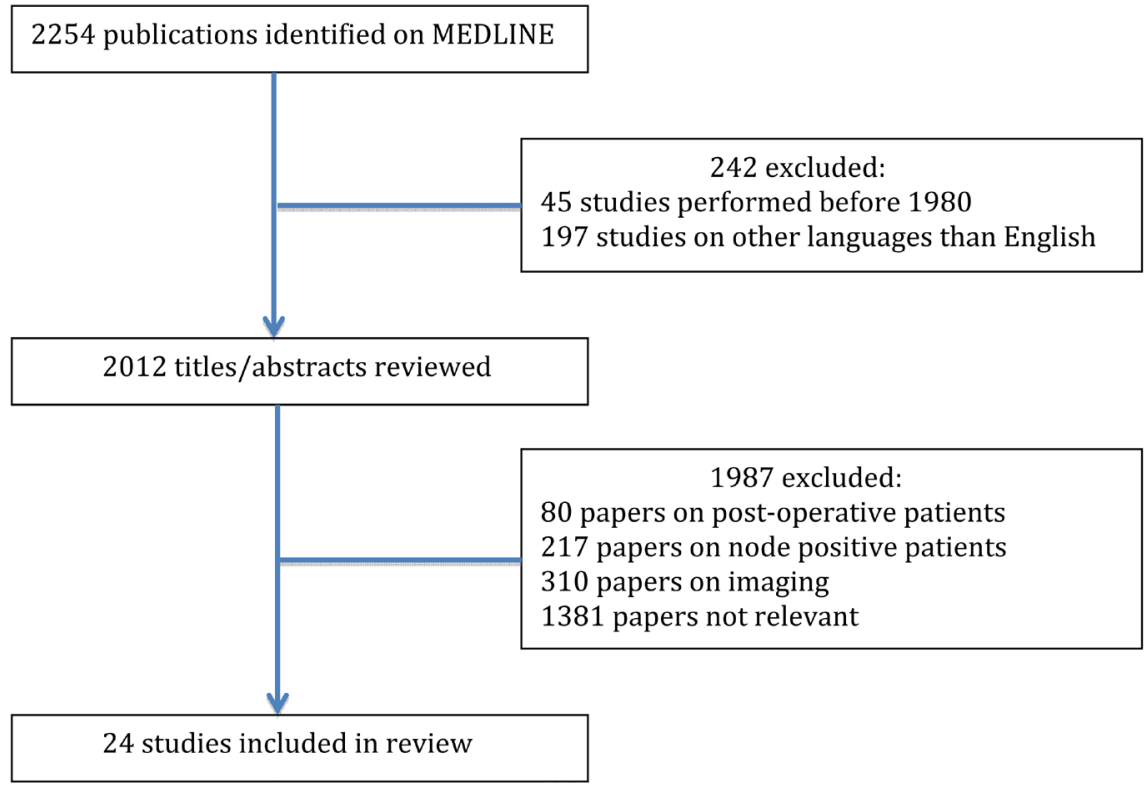

Figure 1. Trial selection. 
reduction of radiation dose needed to destroy $50 \%$ of the tumor volume-TCD50, especially when hormonal treatment was used neoadjuvantly [5].

Whilst this strategy has been widely adopted in low and intermediate risk organ confined disease where at least 6 months of hormonal therapy is given with radiotherapy [6] [7], there still remains much controversy in the context of node positive and high risk disease where the risk of systemic relapse is probably higher than local progression. The addition of radiotherapy has yet to be clearly defined in terms of radiation field, dose required and the optimal duration of hormonal therapy.

For those patients with clinically staged organ confined disease (cN0), there is recognition that regional lymph node metastases can be as high as $40 \%$ in patients with high-risk disease [8]. There are various predictive models that can be used to estimate the risk of lymph node involvement. One commonly used example is the Roach formula based on parameters such as Gleason score and PSA which was developed in the early PSA era, using a cut off level of greater than $15 \%$ to designate high risk patients that would be suitable for pelvic radiotherapy [9].

As such elective pelvic nodal irradiation in those considered at particularly high risk delivered at the same time as prostate radiotherapy was put forward as a strategy for improving clinical outcome, and has been a longstanding therapeutic dilemma, especially given the concerns of bowel toxicity with pelvic irradiation.

High-risk node negative diseaseencompasses aheterogeneous group ranging from T3/T4 tumours, Gleason score 8 - 10 disease (irrespective of the T stage), and for those patients with PSA > 20 (irrespective of T stage or Gleason score). It is this heterogeneity that makes interpretation of trial data difficult. In addition the Roach formula, when applied to a more contemporary cohort probably overestimates lymph node risk and adjustment factors need to be applied [10].

Table 1 shows a summary of the most pivotal prospective randomized trials addressing the issue of combined modality treatment for high risk disease. Most trials involve prostate and pelvic radiotherapy and all show a survival advantage when ADT is added to radiotherapy (RT).

The EORTC 22863 trial was one of the earliest randomized trials to show an improvement in overall survival when RT was added to ADT for high-risk disease and set a benchmark for clinical practice. In this trial 415 patients with T3-T4 or high grade T1-2 disease (all node negative) were randomized to receive either RT alone (50 Gy to the whole pelvis and a prostate boost to $70 \mathrm{~Gy}$ ) or the same RT and an LHRH analogue (monthly Goserelin) starting on the first day of radiotherapy and continuing for 3 years. After a median follow-up of 9.4 years a significant difference in 10-year overall survival was observed for those receiving combined modality treatment $58.1 \%$ vs $39.8 \%, p=0.0004$ [11].

One of the criticisms of this study was that it did not look at what ADT alone may have provided, but this was to be addressed by 2 subsequent trials. 
Table 1. A summary of selected major prospective clinical trials addressing the issue of ADT and RT in the management of high risk prostate cancer.

\begin{tabular}{|c|c|c|c|c|c|c|}
\hline Author & $\begin{array}{l}\text { Study } \\
\text { period }\end{array}$ & $\mathrm{N}$ & Main eligibility & $\mathrm{ADT}$ & RT & Key outcomes \\
\hline $\begin{array}{c}\text { Bolla } \\
(\text { EORTC 22863) } \\
{[11]}\end{array}$ & $1987-1995$ & 415 & $\begin{array}{l}\text { T1-2 high Gleason } \\
\text { grade or T3-4 any } \\
\text { Gleason grade, all } \\
\text { clinically N0. }\end{array}$ & $\begin{array}{l}3 \text { yrs, LHRH } \\
\text { starting on } \\
\text { commencing RT }\end{array}$ & $\begin{array}{c}\text { Prostate and pelvis } \\
70 \mathrm{~Gy} \text { to the prostate } \\
\text { and SV, } 50 \mathrm{~Gy} \text { to the } \\
\text { pelvis }\end{array}$ & $\begin{array}{c}10 \text {-year OS } 58.1 \% \text { vs } 39.8 \% \\
p=0.0004 \text { in favour of RT }+ \text { ADT }\end{array}$ \\
\hline $\begin{array}{c}\text { Roach } \\
\text { (RTOG 86-10) } \\
{[17]}\end{array}$ & $1987-1991$ & 456 & $\begin{array}{l}\text { bulky }(5 \times 5 \mathrm{~cm}) \text { tumors } \\
(\mathrm{T} 2-4) \text { with or without } \\
\text { pelvic lymph node } \\
\text { involvement } \\
33 \% \text { node positive } \\
\text { below the common iliac } \\
\text { chain }\end{array}$ & $\begin{array}{l}4 \text { months ADT } \\
\text { starting } 2 \text { months } \\
\text { before RT }\end{array}$ & $\begin{array}{l}\text { Prostate and pelvis } \\
65 \text { - } 70 \text { Gy to the } \\
\text { prostate and SV, } \\
44 \text { - } 46 \text { Gy to the } \\
\text { pelvis }\end{array}$ & $\begin{array}{c}\text { Ten-year OS }(43 \% v 34 \%) \text { and median } \\
\text { survival times }(8.7 v 7.3 \text { years); }(p=.12) \\
\text { favouring ADT and EBRT, respectively. } \\
10 \text {-year DFS }(11 \% \vee 3 \% ; p<0.0001) \text {, and } \\
\text { BF }(65 \% \vee 80 \% ; p<0.0001) \text { with the } \\
\text { addition of ADT, but no differences were } \\
\text { observed in the risk of fatal cardiac } \\
\text { events. }\end{array}$ \\
\hline $\begin{array}{l}\text { Lawton } \\
\text { (RTOG 85-31) } \\
\text { [34] [35] }\end{array}$ & 1987-1992 & 945 & $\begin{array}{l}(\mathrm{pN}+) \text { or gross } \\
\text { extension of the } \\
\text { palpable primary tumor } \\
\text { beyond the prostate } \\
\text { (clinical Stage } \mathrm{T} 3 \text { ) }\end{array}$ & $\begin{array}{l}\text { Continuous until } \\
\text { disease progression } \\
\text { starting last week of } \\
\text { radiotherapy } \\
\text { (arm 1), or } \\
\text { at time of } \\
\text { relapse (arm 2) }\end{array}$ & $\begin{array}{l}\text { Prostate and pelvis } \\
64-70 \text { Gy to the } \\
\text { prostate and SV, } \\
44 \text { - } 46 \text { Gy to the } \\
\text { pelvis }\end{array}$ & $\begin{array}{l}\text { At } 10 \text { years, the absolute survival rate for } \\
\text { RT + ADT arm vsADT at relapse arm } \\
49 \% \text { vs. } 39 \%, p=0.002) \text {. } \\
10 \text {-year rates for the incidence of distant } \\
\text { metastases and disease-specific mortality } \\
\text { was } 24 \% \text { vs. } 39 \%(p<0.001) \text { and } 16 \% \text { vs. } \\
22 \% \text { ( } p=0.0052) \text {, respectively, both in } \\
\text { favor of the RT + ADT arm. }\end{array}$ \\
\hline $\begin{array}{c}\text { Mason } \\
{[13]}\end{array}$ & $1995-2005$ & 1205 & $\begin{array}{l}\text { T3-4, N0/Nx, M0 or } \\
\text { T1-2 disease with either } \\
\text { PSA }>40 \mu \mathrm{g} / \mathrm{L} \text { or PSA } \\
\text { of } 20 \text { to } 40 \mu \mathrm{g} / \mathrm{L} \text { plus } \\
\text { Gleason score of } 8 \text { to } 10 .\end{array}$ & Continuous & $\begin{array}{l}\text { Prostate and pelvis } \\
65 \text { - } 69 \text { Gy to the } \\
\text { prostate and SV, } 45 \\
\text { Gy to pelvic nodes }\end{array}$ & $\begin{array}{l}\text { At } 8 \text { years, the combined RT and } \\
\text { ADTarm resulted in reduced } \\
\text { disease-specific mortality } \\
\text { (absolute difference }=20 \% ; \mathrm{HR}=0.46 \text { ), } \\
\quad \text { and overall mortality } \\
\text { (absolute difference }=6 \% ; \mathrm{HR}=0.70 \text { ) }\end{array}$ \\
\hline $\begin{array}{c}\text { Roach } \\
\text { (RTOG 94-13) } \\
{[19]}\end{array}$ & 1995-1999 & 1275 & $\begin{array}{c}\text { Risk of lymph node } \\
\text { involvement }>15 \%, \\
\text { node negative } \\
\text { median PSA- } 22.6 \\
\text { ng/mL, } \\
67 \% \text { of patients had T2c } \\
\text { to T4 disease, } \\
72 \% \text { had a GS of } 7 \text { to } 10\end{array}$ & $\begin{array}{l}\text { 2X2 factorial } \\
4 \text { arms } \\
\text { NHT- PORT } \\
\text { NHT-WPRT } \\
\text { AHT-PORT } \\
\text { AHT-WPRT } \\
\text { NHT-4 months } \\
\text { starting } 2 \text { months } \\
\text { before RT }\end{array}$ & $\begin{array}{c}\text { PORT (Prostate) } \\
70.2 \mathrm{~Gy} \\
\text { WPRT } \\
\text { (Prostate and pelvis) } \\
70.2 \text { Gy prostate } \\
50.4 \text { Gy } \\
\text { pelvis }\end{array}$ & $\begin{array}{l}\text { Initial results demonstrated a significant } \\
\text { improvement in 4-year PFS, favouring } \\
\text { WPRT (54\% vs. } 47 \% \text {; } p=0.022) \text {; WPRT } \\
\text { with NCHT had the highest 4-year PFS } \\
\qquad(60 \%) \text {. } \\
\text { Updated results with median follow up of } \\
6.6 \text { years, no statistically significant } \\
\text { differences were found in PFS or OS } \\
\text { between NHT vs. AHT and }\end{array}$ \\
\hline & & & & $\begin{array}{l}\text { AHT-4 months from } \\
\text { completion of RT. }\end{array}$ & & WPRT vs. PO-RT \\
\hline $\begin{array}{l}\text { Widmark } \\
\text { [12] }\end{array}$ & $1996-2000$ & 875 & $\begin{array}{c}\text { Node negative, M0 PSA } \\
<70 \text {. Any T3,or high } \\
\text { grade T1b-T2 } \\
\text { Participants with a PSA } \\
\text { of }>11 \mathrm{ng} / \mathrm{mL} \text { had a } \\
\text { pelvic lymph node } \\
\text { dissection }\end{array}$ & $\begin{array}{l}\text { Continuous } \\
3 \text { months initial MAB, } \\
\text { then anti } \\
\text { androgen therapy } \\
\text { until death }\end{array}$ & $\begin{array}{c}\text { Prostate } \\
50 \text { Gy-prostate and } \\
\mathrm{SV},+20 \text { Gy boost to } \\
\text { prostate }\end{array}$ & $\begin{array}{l}10 \text { yrprostate-cancer-specific mortality } \\
23.9 \% \text { in the ADT alone group vs } 11.9 \% \\
\text { in the ADT plus radiotherapy group } \\
\text { (difference } 12.0 \%, 95 \% \text { CI } 4.9 \%-19.1 \% \text {. }\end{array}$ \\
\hline $\begin{array}{c}\text { Denham } \\
\text { (TROG 96-01) } \\
\text { [21] }\end{array}$ & $1996-2000$ & 802 & $\begin{array}{l}\text { T2b, T2c, T3, and T4 } \\
\text { N0 M0 } \\
(>80 \% \text { high risk })\end{array}$ & $\begin{array}{l}0,3 \text { and } 6 \text { months } \\
\text { ADT } \\
\text { with } 2 \text { and } 5 \text { months } \\
\text { NHT for } 3 \text { and } 6 \\
\text { months } \\
\text { randomisation }\end{array}$ & $\begin{array}{l}\text { Prostate } \\
(66 \mathrm{~Gy})\end{array}$ & $\begin{array}{c}\text { At } 10 \text { years- both } 3 \text { and } 6 \text { months of } \\
\text { hormone therapy significantly reduced } \\
\text { local progression }(\mathrm{HR}=0.49 ; p=0.0005 \\
\text { and } \mathrm{HR}=0.45 ; p=0.0001, \text { respectively), } \\
\text { and improved event-free survival } \\
\mathrm{HR}=0.63 ; p<0.0001 \text { and } \mathrm{HR}=0.51 ; \\
\quad p<0.0001, \text { respectively. }\end{array}$ \\
\hline
\end{tabular}




\section{Continued}

\begin{tabular}{|c|c|c|c|c|c|c|}
\hline $\begin{array}{c}\text { Pommier } \\
\text { (GETUG-01) } \\
{[24]}\end{array}$ & $1998-2004$ & 444 & $\begin{array}{l}\text { T1b-T3, N0 pNx, M0 } \\
21 \% \text { - low risk } \\
(<15 \% \text { - Roach })\end{array}$ & $\begin{array}{l}4 \text { - } 8 \text { months NHT, } \\
\text { plus concurrent } \\
\text { ADT mandatory } \\
\text { for high risk }\end{array}$ & $\begin{array}{l}\text { Prostate and pelvis } \\
66 \text { - } 70 \text { Gy to the } \\
\text { prostate and SV, } \\
44-46 \text { Gy to the } \\
\text { pelvis }\end{array}$ & $\begin{array}{c}\text { No difference between pelvic and PO RT } \\
10 \text {-year OS ( } 74.9 \% \text { vs } 73.6 \%) \text {, or EFS } \\
(57.6 \% \text { vs } 55.6 \%)\end{array}$ \\
\hline $\begin{array}{c}\text { Mottet } \\
{[36]}\end{array}$ & $2000-2003$ & 264 & T3-4 or pT3N0M0 & 3yrs ADT & $\begin{array}{l}\text { Prostate and pelvis } \\
68 \text { - } 70 \mathrm{~Gy} \text { to the } \\
\text { prostate and SV, } 46 \mathrm{~Gy} \\
\text { to pelvic nodes }\end{array}$ & $\begin{array}{c}5 \text { year PFS in favour of ADT }+\mathrm{RT} \text { vs } \\
\mathrm{ADT} \text { alone }(64.7 \% \text { vs } 15.4 \%, p<0.001)\end{array}$ \\
\hline $\begin{array}{c}\text { Blanchard } \\
\text { (GETUG-12) } \\
{[26]}\end{array}$ & $2002-2006$ & 413 & $\begin{array}{l}\text { At least } 1 \text { of the } \\
\text { following high-risk } \\
\text { features: Gleason } \\
\text { score }>8 \text {, stage } \mathrm{T} 3 \text { or } \\
\text { T4 disease, serum PSA } \\
\text { concentration }>20 \\
\text { ng } / \mathrm{mL} \text { or } \mathrm{pN}+\end{array}$ & $\begin{array}{l}3 \text { years ADT } \\
\text { plus } 4 \text { cycles of } \\
\text { Docetaxel } \\
\text { Estramustine }\end{array}$ & $\begin{array}{c}\text { Prostate } \\
\text { (n-208) } \\
74 \text { Gy-prostate and SV } \\
\text { Prostate and pelvis } \\
\text { (n-150) } \\
74 \text { Gy-prostate and SV } \\
46 \text { - } 50 \text { Gy to the pelvis }\end{array}$ & $\begin{array}{l}\text { Median follow-up was } 8.8 \text { years. } \\
\text { No association between bPFS and use of } \\
\text { pelvic ENI in multivariate analysis (HR: } \\
\text { 1.10 [ } 95 \% \text { CI: } 0.78-1.55], p=.60 \text { ), even } \\
\text { when analysis was restricted to pN0 } \\
\text { patients } \\
\text { (HR: } 0.88 \text { [95\% CI: } 0.59-1.31], p=.53 \text { ) }\end{array}$ \\
\hline $\begin{array}{c}\text { Morris } \\
\text { (ASCENDE-RT) } \\
{[27]}\end{array}$ & 2004-2011 & 398 & $\begin{array}{c}\text { At least } 1 \text { of the } \\
\text { following high-risk } \\
\text { features: Gleason } \\
\text { score }>8 \text {, serum PSA } \\
\text { concentration }>20 \\
\text { ng/mL } \\
\text { Excluded if T3b or } \\
\text { greater, } \mathrm{N} 1 \text {, or PSA }>40\end{array}$ & 12 months ADT & $\begin{array}{l}\text { Prostate and pelvis } \\
\text { EBRT } 46 \text { Gy to pelvis } \\
\text { then randomized to } \\
\text { receive DE-EBRT- } 78 \\
\text { Gy or LDR-PB }\end{array}$ & $\begin{array}{l}\text { At median follow-up } 6.5 \text { years } \\
\text { DE-EBRT twice as likely to experience } \\
\text { biochemical failure HR } 2.04 \\
\text { Estimated } 5,7,9 \text { year bPFS- } 89 \%, 86 \% \text {, } \\
83 \% \text { (LDR-PB) vs } 84 \%, 75 \% 62 \% \\
\text { (DE-EBRT) respectively }\end{array}$ \\
\hline
\end{tabular}

SV: seminal vesicles, MAB: maximum androgen blockade, bPFS: biochemical progression free survival, PFS: progression free survival, ENI: elective nodal irradiation, OS: overall survival. DE-EBRT: dose escalated external beam radiotherapy, LDR-PB: low dose rate prostate brachytherapy.

The SPCG-7 trial included 875 patients with locally advanced prostate cancer who were randomly assigned to ADT alone (3 months of total androgen blockade followed by continuous endocrine treatment with the anti-androgen-Flutamide) or to the same ADT combined with local prostate RT. After a median follow-up of 7.6 years the addition of RT to ADT halved the 10-year prostate-specific mortality $(23.9 \%$ vs $11.9 \%)$ and substantially decreased overall mortality (39.4\% vs 29.6\%) [12].

These results were confirmed in a later trial by the PR07 group which randomised 1205 men to lifelong ADT alone, or to prostate and pelvic RT plus lifelong ADT. At 8 years, the combined RT and ADT treatment arm resulted in improvement in disease-specific mortality (absolute difference $=20 \%$; hazard ratio $[\mathrm{HR}]=0.46$ ), and overall mortality (absolute difference $=6 \%$; $\mathrm{HR}=0.70$ ) with a median overall survival of 9.7 years ( $95 \%$ CI, 8.8 to 10.5 years) for patients on the ADT alone arm, compared to 10.9 years (95\% CI, 10.0 to 12.8 years) for patients on the $\mathrm{ADT}+\mathrm{RT}$ arm. Interestingly in the $\mathrm{ADT}$ alone group, $10 \%$ received delayed RT for local progression, suggesting that these results may underestimate the benefit of RT. Although patient on ADT + RT reported a higher frequency of adverse events related to bowel toxicity, these were manageable with only two of 589 patients reporting grade 3 or greater diarrhoea at 24 months after RT [13].

Whilst undoubtedly combined modality treatment with ADT and RT has 
been well established and contributes to improvements in both disease specific and overall survival in high risk prostate cancer there still remains unresolved issues. Broadly speaking 2 main questions arise:

- What is the optimal duration of hormonal therapy?

- Should the pelvic nodes be treated (elective pelvic nodal irradiation-ENI)?

\subsection{Optimal Duration of Hormonal Therapy (ADT)}

The recognition that long term hormonal therapy can be associated with an increased risk of osteoporosis, diabetes and cardiovascular toxicity [14] [15] has stimulated interest in reducing the amount of duration of androgen deprivation when combined with RT.

The RTOG 85-31 was among the first prospective trials to establish the benefit of combined modality treatment in patients with locally advanced disease including node positive disease (either T3 at least or N1). 945 patients were randomized to prostate and pelvic RT (whole pelvis 44 - 46 Gy with a 20 - 25 Gy boost to the prostate) versus the same with the addition of an LHRH (Goserelin) starting at the end of radiation, for at least 2 years and preferably until disease progression. Patients in the RT arm were treated with ADT only at the time of disease progression. At 10 years, treatment with adjuvant ADT improved both disease-specific mortality ( $84 \%$ vs $78 \%, p=0.005)$, and overall survival $(49 \%$ versus $39 \%, p=0.002)$. Interestingly subset analysis by Gleason score showed that ADT did not provide a survival benefit in Gleason $2-6$ patients (57\% vs $51 \%, p=0.26$ ) but did for Gleason 7 (52\% vs $42 \%, p=0.026$ ) and Gleason $8-10$ (39\% vs $26 \%, p=0.0046)$. Disease-specific mortality was only reduced in patients with Gleason $\geq 8$ disease ( $27 \%$ vs $40 \%, p=0.0039$ ) [16].

Further studies conducted by the RTOG in the 1990's examined the addition of 4 months of ADT, given prior to and during radiotherapy. In the RTOG 86-10 trial which looked at patients with predominantly bulky disease, subset analyses demonstrated that 4 months of ADT improved local and distant control as well as survival in Gleason 2 - 6 patients, though in Gleason Score $\geq 7$ patients, there was no demonstrated statistically significant benefit in any outcome [17], suggesting that patients with higher risk factors may need longer than 4 months of androgen deprivation to make a notable impact on the natural history of the disease. This trial was part of a combined meta-analysis of RTOG trials which concluded that patients Gleason Score tumours of $8-10$ or Gleason Score 7 with at least T3 disease benefited from the use of long-term ADT [18].

The RTOG 94-13 study reinforced the idea of at least 4 months ADT which when started at least two months prior to radiotherapy and used in combination with whole pelvic radiotherapy showed an improvement in local control and a trend to overall survival. $70 \%$ of the cohort had GS $>7$ and thus study was unable to answer the question of benefit of androgen deprivation when stratified to Gleason Score [19].

Whilst the initial EORTC trial looked at three years of hormonal treatment, 
both the PR07 and SPCG-7 trials used continuous ADT for men with essentially high-risk disease. A subsequent study by the EORTC (22961) investigated whether a shorter course of ADT could be used in men with locally advanced prostate cancer including node positive disease (T1c-2b/N1-2/M0 or T2c-4/N0-2/M0). In this trial 970 patients who had received radiotherapy plus 6 months of androgen suppression were randomly assigned to two groups either no further treatment (short-term ADT) or to receive 2.5 years of further treatment (long-term ADT). At 5 years overall mortality was found to be higher with short-term than with long-term suppression, as was prostate-cancer specific mortality and all other efficacy endpoints, whereas overall quality of life did not differ significantly between the two groups. As such non-inferiority could not be shown leading the investigators to conclude that short-term ADT was inferior to long-term suppression [20].

The Trans-Tasman Radiation Oncology Group (TROG) 96.01 trial sought to compare RT alone with 3 or 6 months of androgen deprivation (Goserelin together with Flutamide), given before (starting 2 and 5 months prior to radiotherapy, respectively) and during $\mathrm{RT}$, in men with locally advanced prostate cancer (T2b-T4 N0 M0). The study randomized 802 patients of which greater than $80 \%$ were high-risk (PSA $>20 \mathrm{ng} \cdot \mathrm{ml}^{-1}$ or Gleason score $>7$ or stage T2c, T3, T4). Ten-year data showed that compared with radiotherapy alone, both 3 and 6 months of ADT significantly reduced local progression $(\mathrm{HR}=0.49 ; p=$ 0.0005 and $\mathrm{HR}=0.45 ; p=0.0001$, respectively), whilst improving event-free survival ( $\mathrm{HR}=0.63 ; p<0.001$ and $\mathrm{HR}=0.51 ; p<0.0001$, respectively) [21].

Taken together these results seem to suggest that the duration of androgen deprivation seems to be optimal when started neoadjuvantly, and does not necessarily need to be lifelong but probably is optimal when given for a duration of between 6 months to 2 years, with a longer duration of hormonal therapy required for patients with Gleason 8 - 10 tumours.

\subsection{The Benefit of Elective Nodal Irradiation}

Although combined modality treatment for high risk prostate cancer is now well established, the use of elective nodal irradiation remains controversial and practice varies greatly amongst Clinical Oncologists. Some argue that for 'high-risk' disease standard therapy should remain prostate and pelvic radiotherapy with three years of androgen suppression, as this has previously been adopted as standard treatment used in phase III trials. However, there remains some reluctance to using pelvic irradiation due to concerns over the increased risk of acute and late bowel morbidity, in the absence of any survival advantages.

In a large retrospective study analyzing over 14,000 high risk prostate cancer patients from the National Cancer database, whole pelvic radiotherapy did not confer a survival advantage over prostate only radiotherapy [22]. In addition there are now two large randomized phase three studies that have called into question whether there is any clinical advantage to treating the pelvis rather than 
just the prostate only.

As already briefly discussed The RTOG 94-13 trial randomized 1275 patients who had high risk (>15\%) node negative prostate cancer. This was a four-arm study seeking to compare whole pelvic (WP) versus prostate only (PO) RT with either neoadjuvant and concurrent androgen deprivation (NHT) or adjuvant deprivation alone (AHT). NHT was delivered for 4 months, beginning 2 months before RT and continued until radiotherapy was completed, whilst AHT commenced at the completion of radiotherapy for a total duration of 4 months. The results showed that when administered with NHT, there was improved progression-free survival (PFS) with WP compared with PO radiation fields (PFS: 60\% $\mathrm{V}$ $44 \%$ at 4 years, respectively; $p=0.008)$ and improved prostate-specific antigen (PSA) relapse-free survival ( $70 \%$ vs $57 \%$ at 4 years, respectively; $p=0.048$ ). However, no overall survival (OS) differences were observed [19]. The findings suggest that greatest benefit of pelvic radiotherapy seems to be in those with a pelvic lymph node risk of $15 \%-35 \%$.

Subsequently, updated results of RTOG 9413 after a median follow-up time of 6.6 years were published. Althoughno statistically significant differences in PFS or OS between NHT versus AHT and WPRT versus PO radiotherapy were seen, there was however a notable trend towards in PFS $(p=0.065)$ in favour of the WPRT + NHT arm compared with the PORT + NHT and WPRT + AHT arms [23]. This came at the expense of increased grade 3 gastrointestinal toxicity with pelvic radiotherapy (5.1\%, (NHT+WPRT), 1.6\% (both ADT arms) and $0.6 \%$ (NHT +PORT) at 10 years) [24].

The GETUG-01 study randomized 446 patients between 1998 and 2004 with organ confined node negative disease to prostate only versus whole pelvic RT with 6 months of ADT (neoadjuvant and concurrent) allowed for high risk patients (T3, or GS $>6$, or PSA $>3 \mathrm{X}$ ULN). The pelvis was treated with a four field technique to $46 \mathrm{~Gy}$ and the prostate treated to initially $66 \mathrm{~Gy}$ but was subsequently increased to 70Gy as the trial progressed. After a median follow-up of 11.4 years, there was no statistically significant difference in overall survival $(74.9 \%$ vs $73.6 \% \mathrm{p}=0.18)$ or event free survival $(57.6 \%$ vs $55.6 \% \mathrm{p}=0.9715)$ between pelvic or prostate RT [25]. Somewhat surprisingly in a post hoc subgroup analysis there was a $15 \%$ improvement in event free survival for those with a low risk of lymph node involvement ( $<15 \%$-Roach formula), but this was not deemed clinically significant when interpreting data with a limited effective size (approximately $20 \%$ of the cohort), and moreover any advantages were observed predominantly in patients who did not receive any ADT [25].

These observations were also observed in a subgroup analysis of a chemotherapy study performed subsequently by the same group. The GETUG-12 trial randomized 413 patients with high risk disease who had full staging with a lymphadenectomy to receive ADT for 3 years, versus the same with 4 cycles of Docetaxel and Estramustine. Local therapy was administered 3 months after the start of systemic treatment. The use of elective nodal RT was left to the treating Oncologist and this was administered to a dose of 46 Gy in 150 out of 358 patients 
that received radiotherapy. This unplanned analysis on the impact of radiotherapy in this trial failed to demonstrate a benefit of pelvic elective nodal irradiation on biochemical progression free survival in high-risk localized prostate cancer patients. Whilst pelvic lymphadenectomy and pelvic RT did not result in an increased morbidity compared to that with prostate-only RT, radiotherapy seemed to have a negative impact on those with node positive disease, with survival advantages only observed with chemotherapy [26].

In a more recent study, the ASCENDE-RT trial enrolled 398 men, of which just under $70 \%$ of the cohort had high risk disease. After stratification by risk group, the subjects were randomized to a standard arm with 12 months of ADT, pelvic irradiation to $46 \mathrm{~Gy}$, followed by a dose-escalated external beam radiation therapy (DE-EBRT) boost to $78 \mathrm{~Gy}$, or an experimental arm that substituted a low-dose-rate prostate brachytherapy (LDR-PB) boost. Of the 398 trial subjects, 200 were assigned to DE-EBRT boost and 198 to LDR-PB boost. After a median follow-up was 6.5 years, patients who received the LDR-PB boost were twice as likely to be free of biochemical failure, suggesting an improvement in local control, but as yet not demonstrating a survival advantage [27].

But do the results of these trials mean that we should now disregard the issue elective pelvic nodal irradiation in high risk disease? Whilst they have not shown an advantage in overall survival there is a persistent albeit non-statistical significant trend for improvement in local control. In particular the RTOG-9413 was not adequately powered to compare the four treatment arms one against the other. Yet when comparing the WPRT + NHT arm to the PORT + NHT arm there was a trend towards statistical significance in the endpoints of PFS ( $\mathrm{p}=$ 0.023 ) [24]. It is important to note that approximately $50 \%$ of patients in the GETUG-01 trial had a low risk of pelvic nodal involvement, with only approximately $11 \%$ having Gleason 8 or greater tumours, and just 25\% with T3 disease [25]. As such this selection weakens the conclusion about the lack of benefit from WPRT. Conversely in the RTOG-9413 study roughly half of all patients in this study had a pretreatment PSA $>20 \mathrm{ng} / \mathrm{ml}$ and roughly $70 \%$ were clinical T2c to T3 disease [19]. Thus with such high risk disease it could be argued that these patients would be better served with higher radiation does to both the prostate and pelvis.

Alsoin both the GETUG-01 and the RTOG trials the duration of ADT allowed was for either 4 - 8 months or 4 months respectively neither of which would nowadays be considered optimal. With regards to radiotherapy technique the upper border of the pelvic field in the GETUG study was at the spinal level of $\mathrm{S} 1 / \mathrm{S} 2$, and in the RTOG trial was similar in that the maximum field size was 11 $\times 11 \mathrm{cms}$ to the cover the internal and external iliac nodes without coverage of the common iliac nodes. It is widely accepted nowadays that the superior border of the pelvic field should be higher to cover common iliac nodes at the spinal level of L4/L5 [28].

An interesting and somewhat curious observation of the RTOG study trial was that WPRT appeared to be beneficial when hormone therapy was given 
neoadjuvantly and concurrently yet detrimental to survival when hormones were given adjuvantly, and this interaction was not seen in either of the PORT arms. The authors postulate an immune modulation of anti-androgen therapy which causes $T$ cell infiltration of involved lymph nodes such that there is an increase in apoptosis before and during RT which may make the radiation therapy more effective at the doses used to treat the lymph nodes [16].

Although plausible this is somewhat at odds to the observation by Braunstein et al. [29], who analyzed over 3700 patients prostate cancer patients that were treated either WPRT or prostate and seminal vesicle radiotherapy (PSVRT) plus brachytherapy boost with or without a short course of neoadjuvant ADT. Both WPRT and short course ADT were associated with a decreased risk of all cause mortality although a combination of the two did not yield a greater benefit suggesting a shared mechanism for the risk reduction in that either modality were dealing with micro-metastatic disease within the pelvic lymph nodes [29].

Thus the issue of elective pelvic lymph node irradiation still remains contentious despite the plethora of trial data. The dose of $46 \mathrm{~Gy}$ to the pelvis used in the majority of trials may not be enough to sterilize lymph nodes, and the duration of hormonal therapy started neoadjuvantly and continued for a period of at least two years would seem to be a minimal requirement. Furthermore, patient selection seems to be key with probably a greater benefit to be derived from those with much higher risk disease (LN risk $>30 \%$ ). The introduction of highly conformal radiotherapy techniques such as intensity modulated radiotherapy (IMRT) have allowed for greater dose sparing to both the small and large bowel in pelvic radiotherapy [30] with an opportunity for safe dose escalation has provided renewed impetus for both elective pelvic nodal irradiation and boosting involved nodes.

The Royal Marsden have conducted a phase 2 trial-PIVOTAL to address this issue using IMRT with 2 years of ADT for patients with high risk (T3/T4 N0 disease with a greater than $30 \%$ risk of pelvic nodal involvement) disease [31]. 124 patients who received at least 6 - 9 months of neoadjuvant androgen deprivation were then randomized to prostate alone (74 Gy/37f) or $74 \mathrm{~Gy} / 37$ fraction to prostate with $60 \mathrm{~Gy} / 37 \mathrm{f}$ to the pelvis using a simultaneous integrated boost. The contouring of the pelvic lymph nodes were standardized and consensus guidelines developed to allow a greater degree of reproducibility representing a modification of previous RTOG guidelines and the Royal Marsden's own technique [32]. The results of this trial are eagerly awaited.

The RTOG likewise are conducting a further randomised study to look again at the question of using higher radiation doses to the pelvis and prostate with IMRT with or without brachytherapy boost in patients with unfavorable-intermediate or favorable high-risk patients [33]. The pelvic field in comparison to previous RTOG studies will have extended superior coverage to L4/5, together with an opportunity for varying duration of ADT (4, 6 or 32 months beginning approximately 2 months prior to RT). 


\section{Summary}

Combined modality treatment with hormones and radiotherapy represents the standard of care for high risk locally advanced node negative prostate cancer.

The duration of androgen deprivation has to be balanced by the associated risks cardiovascular and metabolic complications, with a longer duration needed for those at greater risk of lymph node involvement and systemic disease. 2 years of androgen deprivation started just prior to radiotherapy represents a benchmark.

It still remains to be determined whether elective nodal irradiation to the pelvis is more beneficial than prostate only radiotherapy, though current image guided conformal radiotherapy techniques allows for an acceptable toxicity profile with prostate and pelvic radiotherapy.

\section{Acknowledgements}

Stephen Edwards, Shalini Mondal, Sohib Ali, Sophia Magwaro, Waqar Salim, Heather Bhola-Stewart, Suraiya Dubash, Annalie Servidad, Tara Barwick, Patti McNaught, Fiona Power, Jonathan Rogers, Jack Doraiswamy, Simon Coughlan, Department of Radiotherapy Charing Cross Hospital.

\section{References}

[1] Zagars, G.K., Pollack, A. and von Eschenbach, A.C. (2001) Addition of Radiation Therapy to Androgen Ablation Improves Outcome for Subclinically Node-Positive Prostate Cancer. Urology, 58, 233-239. https://doi.org/10.1016/S0090-4295(01)01168-2

[2] Lin, C.C., Gray, P.J., Jemal, A. and Efstathiou, J.A. (2015) Androgen Deprivation with or without Radiation Therapy for Clinically Node-Positive Prostate Cancer. Journal of the National Cancer Institute, 107, djv119. https://doi.org/10.1093/jnci/djv119

[3] James, N.D., Spears, M.R., Clarke, N.W., Dearnaley, D.P., Mason, M.D., Parker, C.C., et al. (2016) Failure-Free Survival and Radiotherapy in Patients With Newly Diagnosed Nonmetastatic Prostate Cancer: Data From Patients in the Control Arm of the STAMPEDE Trial. JAMA Oncology, 2, 348-357. https://doi.org/10.1001/jamaoncol.2015.4350

[4] Langenhuijsen, J.F., van Lin, E.N., Hoffmann, A.L., Spitters-Post, I., Alfred Witjes, J., Kaanders, J.H., et al. (2011) Neoadjuvant Androgen Deprivation for Prostate Volume Reduction: The Optimal Duration in Prostate Cancer Radiotherapy. Urologic Oncology, 29, 52-57. https://doi.org/10.1016/j.urolonc.2009.03.024

[5] Zietman, A.L., Prince, E.A., Nakfoor, B.M. and Park, J.J. (1997) Androgen Deprivation and Radiation Therapy: Sequencing Studies Using the Shionogi in Vivo Tumor System. International Journal of Radiation Oncology ${ }^{\star}$ Biology ${ }^{\star}$ Physics, 38, 1067-1070. https://doi.org/10.1016/S0360-3016(97)00309-X

[6] Dearnaley, D.P., Jovic, G., Syndikus, I., Khoo, V., Cowan, R.A., Graham, J.D., et al. (2014) Escalated-Dose versus Control-Dose Conformal Radiotherapy for Prostate Cancer: Long-Term Results from the MRC RT01 Randomised Controlled Trial. Lancet Oncology, 15, 464-473. https://doi.org/10.1016/S1470-2045(14)70040-3 
[7] Dearnaley, D., Syndikus, I., Sumo, G., Bidmead, M., Bloomfield, D., Clark, C., et al. (2012) Conventional versus Hypofractionated High-Dose Intensity-Modulated Radiotherapy for Prostate Cancer: Preliminary Safety Results from the CHHiP Randomised Controlled Trial. Lancet Oncology, 13, 43-54. https://doi.org/10.1016/S1470-2045(11)70293-5

[8] Créhange, G., Chen, C.P., Hsu, C.C., Kased, N., Coakley, F.V., Kurhanewicz, J., et al. (2012) Management of Prostate Cancer Patients with Lymph Node Involvement: A Rapidly Evolving Paradigm. Cancer Treatment Reviews, 38, 956-967. https://doi.org/10.1016/j.ctrv.2012.05.005

[9] Roach, M., Marquez, C., You, H.S., Narayan, P., Coleman, L., Nseyo, U.O., et al. (1994) Predicting the Risk of Lymph Node Involvement Using the Pre-Treatment Prostate Specific Antigen and Gleason Score in Men with Clinically Localized Prostate Cancer. International Journal of Radiation Oncology ${ }^{\star}$ Biology ${ }^{\star}$ Physics, 28, 33-37. https://doi.org/10.1016/0360-3016(94)90138-4

[10] Nguyen, P.L., Chen, M.-H., Hoffman, K.E., Katz, M.S. and D’Amico, A.V. (2009) Predicting the Risk of Pelvic Node Involvement among Men with Prostate Cancer in the Contemporary Era. International Journal of Radiation Oncology ${ }^{*}$ Biology Physics, 74, 104-109. https://doi.org/10.1016/j.ijrobp.2008.07.053

[11] Bolla, M., Van Tienhoven, G., Warde, P., Dubois, J.B., Mirimanoff, R.-O., Storme, G., et al. (2010) External Irradiation with or without Long-Term Androgen Suppression for Prostate Cancer with High Metastatic Risk: 10-Year Results of an EORTC Randomised Study. Lancet Oncology, 11, 1066-1073. https://doi.org/10.1016/S1470-2045(10)70223-0

[12] Widmark, A., Klepp, O., Solberg, A., Damber, J.-E., Angelsen, A., Fransson, P., et al. (2009) Endocrine Treatment, with or without Radiotherapy, in Locally Advanced Prostate Cancer (SPCG-7/SFUO-3): An Open Randomised Phase III Trial. Lancet, 373, 301-308. https://doi.org/10.1016/S0140-6736(08)61815-2

[13] Mason, M.D., Parulekar, W.R., Sydes, M.R., Brundage, M., Kirkbride, P., Gospodarowicz, M., et al. (2015) Final Report of the Intergroup Randomized Study of Combined Androgen-Deprivation Therapy Plus Radiotherapy versus AndrogenDeprivation Therapy Alone in Locally Advanced Prostate Cancer. Journal of Clinical Oncology, 33, 2143-2150. https://doi.org/10.1200/JCO.2014.57.7510

[14] O’Farrell, S., Garmo, H., Holmberg, L., Adolfsson, J., Stattin, P. and Van Hemelrijck, M. (2015) Risk and Timing of Cardiovascular Disease after Androgen-Deprivation Therapy in Men with Prostate Cancer. Journal of Clinical Oncology, 33, 1243-1251. https://doi.org/10.1200/JCO.2014.59.1792

[15] Saylor, P.J. and Smith, M.R. (2013) Metabolic Complications of Androgen Deprivation Therapy for Prostate Cancer. The Journal of Urology, 189, S34-S42; discussion S43-S44.

[16] Roach, M., Yan, Y., Lawton, C.A., Hsu, I.-C.J., Lustig, R.A., Jones, C.U., et al. (2012) Radiation Therapy Oncology Group (RTOG) 9413: Randomized Trial Comparing Whole Pelvic Radiotherapy (WPRT) to Prostate Only (PORT) and Neoadjuvant Hormone Therapy (NHT) to Adjuvant Hormone Therapy (AHT). Journal of Clinical Oncology, 30, 96. https://doi.org/10.1200/jco.2012.30.5_suppl.96

[17] Roach, M., Bae, K., Speight, J., Wolkov, H.B., Rubin, P., Lee, R.J., et al. (2008) ShortTerm Neoadjuvant Androgen Deprivation Therapy and External-Beam Radiotherapy for Locally Advanced Prostate Cancer: Long-Term Results of RTOG 8610. Journal of Clinical Oncology, 26, 585-591. https://doi.org/10.1200/JCO.2007.13.9881 
[18] Roach III, M., Lu, J., Pilepich, M.V., Asbell, S.O., Mohiuddin, M., Terry, R., et al. (2000) Predicting Long-Term Survival, and the Need for Hormonal Therapy: A Meta-Analysis of RTOG Prostate Cancer Trials. International Journal of Radiation Oncology ${ }^{\star}$ Biology ${ }^{\star}$ Physics, 47, 617-627. https://doi.org/10.1016/S0360-3016(00)00577-0

[19] Roach, M., DeSilvio, M., Lawton, C., Uhl, V., Machtay, M., Seider, M.J., et al. (2003) Phase III Trial Comparing Whole-Pelvic versus Prostate-Only Radiotherapy and Neoadjuvant versus Adjuvant Combined Androgen Suppression: Radiation Therapy Oncology Group 9413. Journal of Clinical Oncology, 21, 1904-1911. https://doi.org/10.1200/JCO.2003.05.004

[20] Bolla, M., de Reijke, T.M., Van Tienhoven, G., Van den Bergh, A.C.M., Oddens, J., Poortmans, P.M.P., et al. (2009) Duration of Androgen Suppression in the Treatment of Prostate Cancer. New England Journal of Medicine, 360, 2516-2527. https://doi.org/10.1056/NEJMoa0810095

[21] Denham, J.W., Steigler, A., Lamb, D.S., Joseph, D., Turner, S., Matthews, J., et al. (2011) Short-Term Neoadjuvant Androgen Deprivation and Radiotherapy for Locally Advanced Prostate Cancer: 10-Year Data from the TROG 96.01 Randomised Trial. The Lancet Oncology, 12, 451-459.

[22] Amini, A., Jones, B.L., Yeh, N., Rusthoven, C.G., Armstrong, H. and Kavanagh, B.D. (2015) Survival Outcomes of Whole-Pelvic versus Prostate-Only Radiation Therapy for High-Risk Prostate Cancer Patients with Use of the National Cancer Data Base. International Journal of Radiation Oncology, Biology, Physics, 93, 1052-1063. https://doi.org/10.1016/j.ijrobp.2015.09.006

[23] Lawton, C.A., DeSilvio, M., Roach, M., Uhl, V., Kirsch, R., Seider, M., et al. (2007) An Update of the Phase III Trial Comparing Whole Pelvic to Prostate Only Radiotherapy and Neoadjuvant to Adjuvant Total Androgen Suppression: Updated Analysis of RTOG 94-13, with Emphasis on Unexpected Hormone/Radiation Interactions. International Journal of Radiation Oncology, Biology, Physics, 69, 646-655. https://doi.org/10.1016/j.ijrobp.2007.04.003

[24] Roach, M., Hunt, D., Lawton, C.A., Hsu, I., Lustig, R.A., Seider, M., et al. (2013) Radiation Therapy Oncology Group (RTOG) 9413: A Randomized Trial Comparing Whole Pelvic Radiation Therapy (WPRT) to Prostate Only (PORT) and Neoadjuvant Hormonal Therapy (NHT) to Adjuvant Hormonal Therapy (AHT). International Journal of Radiation Oncology, Biology, Physics, 87, S106-S107. https://doi.org/10.1016/j.ijrobp.2013.06.275

[25] Pommier, P., Chabaud, S., Lagrange, J.-L., Richaud, P., Le Prise, E., Wagner, J.-P., et al. (2016) Is There a Role for Pelvic Irradiation in Localized Prostate Adenocarcinoma? Update of the Long-Term Survival Results of the GETUG-01 Randomized Study. International Journal of Radiation Oncology, Biology, Physics, 96, 759-769. https://doi.org/10.1016/j.ijrobp.2016.06.2455

[26] Blanchard, P., Faivre, L., Lesaunier, F., Salem, N., Mesgouez-Nebout, N., Deniau-Alexandre, E., et al. (2016) Outcome According to Elective Pelvic Radiation Therapy in Patients with High-Risk Localized Prostate Cancer: A Secondary Analysis of the GETUG 12 Phase 3 Randomized Trial. International Journal of Radiation Oncology, Biology, Physics, 94, 85-92. https://doi.org/10.1016/j.ijrobp.2015.09.020

[27] Morris, W.J., Tyldesley, S., Rodda, S., Halperin, R., Pai, H., McKenzie, M., et al. (2017) Androgen Suppression Combined with Elective Nodal and Dose Escalated Radiation Therapy (the ASCENDE-RT Trial): An Analysis of Survival Endpoints for a Randomized Trial Comparing a Low-Dose-Rate Brachytherapy Boost to a Dose-Escalated External Beam Boost for High- and Intermediate-Risk Prostate Cancer. International Journal of Radiation Oncology, Biology, Physics, 98, 275-285. 
https://doi.org/10.1016/j.ijrobp.2016.11.026

[28] Spratt, D.E., Vargas, H.A., Zumsteg, Z.S., GoliaPernicka, J.S., Osborne, J.R., Pei, X., et al. (2016) Patterns of Lymph Node Failure after Dose-Escalated Radiotherapy: Implications for Extended Pelvic Lymph Node Coverage. European Urology. https://doi.org/10.1016/j.eururo.2016.07.043

[29] Braunstein, L.Z., Chen, M.-H., Dosoretz, D.E., Salenius, S.A., Katin, M.J., Nanda, A., et al. (2015) Whole Pelvis versus Prostate-Only Radiotherapy with or without Short-Course Androgen Deprivation Therapy and Mortality Risk. Clinical Genitourinary Cancer, 13, 555-561. https://doi.org/10.1016/j.clgc.2015.04.010

[30] Nutting, C.M., Convery, D.J., Cosgrove, V.P., Rowbottom, C., Padhani, A.R., Webb, S., et al. (2000) Reduction of Small and Large Bowel Irradiation using an Optimized Intensity-Modulated Pelvic Radiotherapy Technique in Patients with Prostate Cancer. International Journal of Radiation Oncology, Biology, Physics, 48, 649-656. https://doi.org/10.1016/S0360-3016(00)00653-2

[31] Study of Prostate and pelvis versus pros Tate Alone Treatment for Locally Advanced Prostate Cancer (PIVOTAL). https://clinicaltrials.gov/ct2/show/NCT01685190

[32] Harris, V.A., Staffurth, J., Naismith, O., Esmail, A., Gulliford, S., Khoo, V., et al. (2015) Consensus Guidelines and Contouring Atlas for Pelvic Node Delineation in Prostate and Pelvic Node Intensity Modulated Radiation Therapy. International Journal of Radiation Oncology, Biology, Physics, 92, 874-883. https://doi.org/10.1016/j.ijrobp.2015.03.021

[33] RTOG 0924 Protocol Information. https://www.rtog.org/ClinicalTrials/ProtocolTable/StudyDetails.aspx?study=0924

[34] Lawton, C.A., Winter, K., Byhardt, R., Sause, W.T., Hanks, G.E., Russell, A.H., et al. (1997) Androgen Suppression plus Radiation versus Radiation Alone for Patients with D1 (pN+) Adenocarcinoma of the Prostate (Results Based on a National Prospective Randomized Trial, RTOG 85-31). Radiation Therapy Oncology Group. International Journal of Radiation Oncology, Biology, Physics, 38, 931-939. https://doi.org/10.1016/S0360-3016(97)00288-5

[35] Lawton, C.A., Winter, K., Murray, K., Machtay, M., Mesic, J.B., Hanks, G.E., et al. (2001) Updated Results of the Phase III Radiation Therapy Oncology Group (RTOG) Trial 85-31 Evaluating the Potential Benefit of Androgen Suppression Following Standard Radiation Therapy for Unfavorable Prognosis Carcinoma of the Prostate. International Journal of Radiation Oncology, Biology, Physics, 49, 937-946. https://doi.org/10.1016/S0360-3016(00)01516-9

[36] Mottet, N., Peneau, M., Mazeron, J.-J., Molinie, V. and Richaud, P. (2012) Addition of Radiotherapy to Long-Term Androgen Deprivation in Locally Advanced Prostate Cancer: An Open Randomised Phase 3 Trial. European Urology, 62, 213-219. https://doi.org/10.1016/j.eururo.2012.03.053 